\title{
PERBANDINGAN DALAM PEMILIHAN PRINTER MENGGUNAKAN METODE WEIGHT PRODUK
}

\author{
Hapidzul Nurinadi ${ }^{1)}$, Yulrio Brianorman ${ }^{2)}$ \\ ${ }^{1,2)}$ Informatika, Teknik dan Universitas Muhammadiyah Pontianak, JL.Ahmad Yani No.111, Bangka \\ Belitung Laut, Kec. Pontianak Tenggara, Kota Pontianak, Kalimantan Barat, 78123. \\ 192220086@unmuhpnk.ac.id
}

\footnotetext{
Riwayat

Diterima 3 Sept

2020

Revisi 1 Oct,

2020

Disetujui 12 Nov 2020

Terbit $30 \mathrm{Nov}$ 2020

Kata Kunci Sistem

Pendukung

Keputusan,

Weight Produk

Printer
}

\begin{abstract}
Article history Received Sep 15 , 2020

Revised Okt 17, 2020

Accepted Nov 22 2020

Available online Nov 30, 2020

Keywords Decision Support System, Weight Product, Printer

Abstract - aking decision support system consideration on a printer product is important at the stage of using the value specifications that exist on the printer itself, ignorance of the advantages and disadvantages of the types of printer types can make a loss to the user because there are many choices of printer types sold in the market or online shop. But there is a way to overcome this problem by using a decision support system in order to be able to choose the right goods and according to the needs of users that are needed later, it needs to be done to reduce errors in assessing the printer not only on specifications but also on price. Product Weight Method is a multiplication method to link the attribute rating, where each attribute must be raised first with the attribute weight, Product Weight is often used to assist in determining the purchase decision of a product. The product weight method was chosen because it is suitable in making a comparison decision in choosing a Printer based on the criteria obtained from the Printer specifications and prices. The methodology used is only the stages of the evaluation criteria consisting of price, Color Print speed, Black and White print speed and Print Weight. The results of a search using the product weight method are for consideration in determining the purchase of a printer to be able to match the needs of its user criteria.
\end{abstract}

Keywords: Decision Support System, Weight Product, Printer

\section{Abstrak}

Abstrak - Pengambilan sistem pendukung keputusan pertimbangan pada suatu produk Printer merupakan hal yang penting pada tahap menggunakan nilai spesifikasi yang ada pada Printer itu sendiri, ketidaktahuan kelebihan dan kekurangan pada jenis type printer merupakan bisa membuat kerugian pada pengguna karena ada banyak nya pilihan type jenis printer yang dijual dipasaran atau toko online. Tetapi ada cara untuk mengatasi masalah tersebut yaitu menggunakan sistem pendukung keputusan agar dapat memlih barang yang tepat dan sesuai kebutuhan pengguna yang diperlukan nanti nya, perlu di lakukan untuk mengurangi kesalahan dalam memberikan penilaian terhadap Printer tidak hanya pada spesifikasi tetapi dari harganya juga. Metode Weight Produk adalah metode perkalian untuk menghubungkan rating atribut, dimana setiap atribut harus dipangkatkan dulu dengan bobot atribut, Weight Produk sering digunakan untuk membantu dalam menentukan keputusan pembelian sebuah produk. Metode weight produk di pilih karena cocok dalam pengambilan keputusan sebuah perbandingan dalam memilih printer berdasarkan kriteria yang di dapat dari spesifikasi dan harga printer. Metodologi yang di gunakan hanya tahapan dari penilaian kriteria yang terdiri dari harga, kecepatan print berwarna, kecepatan print hitam putih dan berat print tersebut. Hasil dari pencarian menggunakan metode weight produk adalah untuk bahan pertimbangan dalam menentukan pemilihan pembelian sebuah printer agar dapat sesuai kebutuhan kriteria pengguna nya.

Kata kunci: Sistem Pendukung Keputusan, Weight Produk, Printer 


\section{Pendahuluan}

Seiring perkembangan teknologi informasi yang sangat maju dan cukup pesat di Indonesia, hampir semua kalangan memiliki printer sebagai alat bantu yang di gunakan sebagai media cetak, sehingga keberadaan printer di dalam rumah sudah tidak asing lagi di masyarakat Indonesia yang efisien dalam membantu proses pengerjaan (Amriana, dkk, 2020).

Printer merupakan sebuah alat yang digunakan untuk mencetak gambar ataupun tulisan ke media kertas. Menurut Lim Rusyamsi (2009:1) "Printer merupakan sebuah perangkat keras yang dihubungkan pada komputer yang berfungsi untuk menghasilan cetakan baik berupa tulisan ataupun gambar dari komputer pada media kertas atau yang sejenisnya". Jenis printer ada tiga macam, yaitu jenis Printer Dot metrix, printer Ink jet, dan printer Laser jet.

Kehadiran printer sangat memberikan manfaat tetapi disamping itu juga terdapat permasalahan yang sering terjadi pada mesin printer yaitu sering terjadi kerusakan pada mesin printer yang ditimbulkan akibat kurangnya pengetahuan pemakai dalam merawat ataupun dalam penggunaan pemakaian secara berulang pada printer tersebut. Gejala-gejala yang sering terjadi pada kerusakan printer adalah printer tidak menyala, warna tidak keluar, kertas tidak mau turun, catridge tidak terbaca dan sebagainya. Merawat printer tidaklah sesulit kedengarannya, bahkan bisa di anggap mudah, dan jika perawatannya kita lakukan dengan benar, maka umur printer akan bertambah.

Berikut contoh permasalahan yang biasa di alami oleh printer menurut (Pardede \& Ginting, 2013). antara lain :

1. Printer tidak bisa hidup. Hal ini sering terjadi disaat anda mau mencetak ternyata printer tidak bisa hidup. Hal ini disebabkan oleh beberapa hal antara lain:

a. Kabel power listrik belum terhubung dengan printer atau tidak terpasang dengan baik.

b. Kabel power menuju listrik putus. c. Sekring pada printer putus.

d. Printer memang sudah rusak secara fisik.

2. Printer hidup tapi tidak bisa mencetak. Permasalahan ini sering muncul saat anda mau mencetak dengan printer. Meskipun printer sudah terhubung kadang tidak bisa mencetak. Hal-hal yang menyebabkan printer tidak dapat mencetak meskipun printer sudah menyala adalah :

a. Cartridge atau pita belum atau tidak terpasang dengan baik.

b. Kertas belum terpasang.

c. Tinta untuk mencetak telah habis.

d. Pada saat melakukan cetak anda salah memasukkan halaman untuk dicetak.

3. Printer mencetak tetapi tidak sampai selesai. Hal-hal yang menyebabkan printer mencetak tidak sampai habis adalah :

a. Pada saat sedang mencetak tinta printer habis.

b. Pada saat sedang mencetak tibatiba listrik mati.

c. Pada saat mencetak tiba-tiba anda menutup program aplikasi tersebut.

4. Hasil cetakan printer cacat. Permasalahan lain adalah antara lain :

a. Hasil cetakan terpotong. Hal ini bisa terjadi karena tidak lengkapnya jarum pengetuk pada printer, atau memang karena ada kerusakan pada device drivernya.

b. Cetakan melompat-lompat. Hal ini sering terjadi pada printer jenis dot matrik. Penyebabnya adalah tidak lancarnya gerakan printer head akibat kotor, atau tersumbat sesuatu.

c. Tinta tumpah ke dalam cetakan.

d. Printer tidak bisa mencetak gambar.

5. Printer tidak terdeteksi oleh sistem. Permasalahan ini biasanya dapat diatasi melalui instalasi driver printer ulang.

6. Lampu indikator pada printer berkedip terus. Permasalahan seperti ini muncul setelah pengisian tinta, dan dapat diatasi dengan melakukan reset tinta printer. 
Saat ini printer sudah memiliki berbagai merk serta fasilitas-fasilitas pendukung yang ada didalamnya salah satu merk printer yang sering digunakan di Pontianak adalah merk Epson, Canon dan hp. Dari penjelasan diatas penulis tertarik untuk membuat perbandingan terhadap kualitas dari ketiga merk printer tersebut dalam bentuk sistem pendukung keputusan yang bertujuan membantu individu dalam memilih printer dengan kualitas baik yang membandingkan beberapa spesifikasi printer.

Menurut Prof. Marimin (dalam sitohang \& siboro, 2016) mengungkapkan bahwa konsep Sistem Pengambilan Keputusan (SPK) muncul pertama kali pada awal tahun 1970 oleh Scott-Morton. Mereka mendefenisikan bahwa sistem pengambilan keputusan merupakan suatu sistem interaktif berbasis komputer yang dapat membantu para pengambil keputusan dalam menggunakan data dan model untuk memecahkan persoalan yang bersifat tidak terstruktur.

Untuk itu , metode dari sistem pendukung keputusan yang di gunakan saat ini adalah metode weight produk, metode ini sangat fleksibilitas untuk di pahami. Menurut Yoon (dalam buku Kusumadewi, 2006), metode weighted product menggunakan teknik perkalian untuk menghubungkan rating atribut, dimana rating tiap atribut harus dipangkatkan terlebih dahulu dengan bobot atribut yang bersangkutan (K.P, dkk, 1989).

\section{Metode Penelitian}

MADM adalah suatu metode yang digunakan untuk mencari alternatif paling optimal dari sejumlah alternatif optimal dengan kriteria tertentu. Inti dari MADM adalah menentukan nilai bobot untuk setiap atribut, kemudian dilanjutkan dengan proses perangkingan yang akan menyeleksi alternatif yang sudah diberikan [5].

Pada tahap ini, data dikumpulkan sehingga data implementasi metode yang di buat sesuai dengan kebutuhan pengguna flashdisk. Untuk memperoleh data, $(S)$ digunakan menggunakan data asli dari spesifikasi yang di dapat dari flashdisk yang akan di gunakan.

\section{Metode Weighted Product}

Metode weighted product memerlukan proses normalisasi karena metode ini mengalikan hasil penilaian setiap atribut. Hasil perkalian tersebut belum bermakna jika belum dibandingkan (dibagi) dengan nilai standart. Bobot untuk atribut manfaat berfungsi sebagai pangkat positif dalam proses perkalian, sementara bobot biaya berfungsi sebagai pangkat negative. Untuk itu metode weight produk di buat, ialah unuk menyelesaikan MADM. Langkah yang di gunakan untuk menyelesaikan metode weight produk adalah :

\section{Menentukan Kriteria}

Kriteria di tentukan untuk menjadi acuan dalam pengambilan keputusan di metode weight produk.

\section{Normalisasi bobot}

Melakukan normalisasi untuk menghasilakan nilai $\boldsymbol{W}_{\boldsymbol{j}}$ adalah nilai tambah dari kriteria $\mathrm{j} 1, \mathrm{j} 2, \ldots, \mathrm{n}$ dan di bagi oleh $\mathrm{j} 1, \mathrm{j} 2$, $\ldots, \mathrm{n}$.

$$
W j \frac{W_{j}}{\sum W_{j}}
$$

\section{Menentukan Vektor (S)}

Dimana $\sum w j=1$. wj adalah pangkat bernilai positif untuk atribut keuntungan (benefit), dan bernilai negatif untuk atribut biaya (cost).

Dengan cara mengarahkan seluruh kriteria dengan hasil dari normalisasi alternatif yang berpangkat positif dan negatif.

$$
S_{i}=\prod_{j}^{n}=1 X_{i j} W_{j}
$$

\section{Menentukan Vector (V)}

Untuk menetukan nilai vector disini merupakan tahap akhir yang di gunakan untuk mencari perangkingan di mana jumlah nilai vector

$$
V_{i}=\frac{\prod_{j}^{n}=1 X i j^{W j}}{\prod_{j}^{n}=1(X j)^{W j}}
$$


Keterangan dari langkah weight produk 1-5 :

- $\quad \mathrm{S}$ : menyatakan preferensi alternatif yang dianalogikan sebagai vektor $\mathrm{S}$

- V : menyatakan preferensi alternatif yang dianalogikan sebagai vektor $\mathrm{V}$

- $\quad \mathrm{x}$ : menyatakan nilai kriteria

- w : menyatakan bobot kriteria

- i : menyatakan alternatif

- $\mathrm{j}$ : menyatakan kriteria

- $\mathrm{n}$ : menyatakan banyaknya kriteria

\section{A. Tahap Perencanaan}

Yang digunakan untuk penyelesaian metode ini hanya menggunakan survei memlalui kuisioner terhadap pegawai di BPKD Pontianak. Dimana data yang di gunakan di dapat dari spesifikasi dan harga yang di dapat melalui toko online pada tahun 2020. Batasan lain dalam metode penelitian ini yaitu ada 3 type merek dengan harga yang yang berbeda-beda yaitu Epson 2.298.000, Canon 3.287.000, dan HP 1,550.000.

\section{B. Tahap Analisis}

Dari hasil data yang di dapat, ada 4 (empat) kriteria yang di jadikan pertimbangan dalam memilih printer untuk pengguna yaitu :

\section{Harga}

Harga menjadikan pertimbangan dimana banya pengguna yang pasti menginginkan harga murah tetapi kualitas yang bagus.

2. Print Warna

Dimana harus tau printer yang mampu memprint kertas dalam type berwarna dalam jumlah batasan terhadap print tersebut.

3. Print Hitam

Membaca perintah data untuk melakukan print dengan cepat dan rapi tentunya

4. Berat

Berat sebuah printer juga sebagai pertimbangan agar nantinya mudah untuk dipindah pindahkan ke suatu ruangan lain nya
Adapun gambaran singkat yang dapat di berikan untuk bisa lebih mudah memahami alur yang digunakan dalam metode ini, bisa di lihat pada tabel 1-3.

Tabel 1. Masukan

\begin{tabular}{c}
\hline 1.Masukan \\
\hline Harga \\
Print Warna \\
Print Hitam Putih \\
Berat Print \\
\hline Tabel 2. Metode \\
\hline 2.Metode Weight Produk \\
\hline Menentukan Kriteria \\
Normalisasi bobot \\
Menentukan Vektor (S) \\
Menentukan Vektor (V) \\
\hline \multicolumn{2}{c}{ Tabel 3. Hasil } \\
\hline \multicolumn{2}{c}{ 3.Hasil } \\
\hline Perangkingan dengan hasil \\
tertinggi yang akan di pilih \\
menjadi pilihan utama pada \\
pembelian Printer untuk \\
kantor \\
\hline
\end{tabular}

\section{Hasil dan Pembahasan}

A. Menentukan Alternatif, Kriteria, Bobot dan Jenis

\section{Tabel Kriteria}

Menentukan nilai pada kriteria untuk setiap alternatif. Di langkah ini terdapat 3 alternatif dengan 4 kriteria dan jenis yang diujikan yang dapat di lihat pada table 1 dan untuk menentukan bobot pada table 2 .

Tabel 4. Kriteria dan jenis

\begin{tabular}{ccc}
\hline Kriteria & Jenis & Keterangan \\
C1 & Cost & Harga \\
C2 & Benefit & Print \\
& & warna \\
C3 & Benefit & $\begin{array}{c}\text { Print } \\
\text { Hitam }\end{array}$ \\
C4 & Benefit & Berat \\
\hline
\end{tabular}

Table 5. Penetuan bobot harga

\begin{tabular}{cc} 
Nilai & Kriteria Harga \\
\hline 1 & $>3000.000$ \\
& $>1.500 .000-$ \\
2 & 2000.000 \\
& $>1000.000-$ \\
3 & 1.500 .000 \\
4 & $>800.000-1000.000$ \\
5 & $0-800.000$ \\
\hline
\end{tabular}


Table 6. Penetuan bobot Print Warna

\begin{tabular}{cc} 
Nilai & Kriteria Print Warna \\
\hline 1 & 20 \\
2 & 15 \\
3 & 18
\end{tabular}

Table 7. Penetuan bobot Hitam Putih

\begin{tabular}{cc}
\hline Nilai & $\begin{array}{c}\text { Kriteria Print W } \\
\text { Hitam }\end{array}$ \\
\hline 1 & 32 \\
2 & 20 \\
3 & 25 \\
\multicolumn{2}{c}{ Table 8. Penetuan bobot Berat } \\
\hline Nilai & Kriteria Berat \\
\hline 1 & $2,3 \mathrm{Kg}$ \\
2 & 3,42 \\
3 & 6,3
\end{tabular}

Keterangan :

Benefit : adalah kriteria yang dapat bernilai plus (menguntungkan).

Cost : adalah kriteria yang dapat bernilai min (tidak menguntungkan).

Bobot : bobot ditentukan oleh spesifikasi dan harga asli yang di dapat dari toko online di sesuaikan dengan kriteria.

sehingga pembagian pada bobot untuk kriteria tidak jauh jaraknya namun tetap dapat memisahkan kriteria bersifat benefit dan cost, bobot dapat dirubah sewaktu-waktu apabila ada penambahan kriteria baru di pemilihan printer yang jadi pertimbangan.

\section{Tabel Alternatif}

Tabel alternatif disini berisikan nama produk 3 jenis type printer yang akan di pertimbangkan, dapat dilihat pada tabel 9 .

Tabel 9.alternatif

\begin{tabular}{cc}
\hline Nama Printer & Alternatif \\
\hline Epson L3110 & A1 \\
HP DeskJet 2135 & A2 \\
Canon PIXMA & A3 \\
G3010 & \\
\hline
\end{tabular}

\section{Tabel Alternatif dan Bobot Kriteria}

Tabel alternative awal dan masing bobot kriteria yang akan di rangkingkan dapat di lihat pada tabel 10 dan 11.

Tabel 10. Alternatif awal printer

\begin{tabular}{c|c|c|c|c}
\hline $\begin{array}{c}\text { Altenat } \\
\text { if }\end{array}$ & harga & $\begin{array}{c}\text { Warn } \\
\mathrm{a}\end{array}$ & $\begin{array}{c}\text { Hita } \\
\mathrm{m} \\
\text { Puti } \\
\mathrm{h}\end{array}$ & $\begin{array}{c}\text { Bera } \\
\mathrm{t}\end{array}$ \\
\hline A1 & 2.200 .000 & 20 & 32 & 2,3 \\
A2 & 1.500 .000 & 15 & 20 & 3,42 \\
A3 & 3.200 .000 & 18 & 25 & 6,3 \\
\hline
\end{tabular}

Selain itu bobot prefensi yang dijadikan sebagai pengujian didapatkan dari hasil kuisioner dimana user memilih tingkat kepentingan yang sesuai dengan kebutuhan dalam memilih Printer.

Tabel 12. Nilai Bobot untuk Setiap Kriteria

\begin{tabular}{|c|c|c|}
\hline Kriteria & Bobot & Tingkat Kepentingan \\
\hline C1 & 3 & Penting \\
\hline C2 & 4 & Sangat Penting \\
\hline C3 & 4 & Sangat Penting \\
\hline C4 & 2 & Cukup Penting \\
\hline
\end{tabular}

Tabel 12 merupakan simulasi nilai bobot untuk setiap kriteria yang dicocokkan dengan sistem pada saat user memilih tingkat kepentingan dari masing-masing kriteria yaitu Harga dengan bobot 3 (penting), Kecepatan Print Warna dengan bobot 4 (sangat penting), Kecepatan Print Hitam dengan bobot 4 (sangat penting) dan Berat dengan bobot 2 (cukup penting).

\section{B. Penentuan Normalisasi Bobot, Vektor S, dan Vektor V}

Bobot yang diketahui tersebut kemudian dilakukan normalisasi bobot/perbaikan bobot, menentukan vektor $\mathrm{S}$ (preferensi kriteria) dan terakhir mencari nilai vektor V (preferensi alternatif) yang akan digunakan untuk perangkingan alternatif.

1. Normalisasi Bobot

$$
\begin{aligned}
\mathrm{W}_{1} & =\frac{3}{3+4+4+2}=0,230 \\
\mathrm{~W}_{2} & =\frac{4}{3+4+4+2}=0,310 \\
\mathrm{~W}_{3} & =\frac{4}{3+4+4+2}=0,310 \\
\mathrm{~W}_{4} & =\frac{2}{3+4+4+2}=0,153
\end{aligned}
$$

2. Menentukan Vektor $S$

$$
\begin{aligned}
& \mathrm{S}_{1}=\left(2 \mathrm{jt}^{-0,230}\right) *\left(20^{0,310}\right) *\left(32^{0,310}\right) *\left(2,3^{0,153}\right) \\
& \quad=0,2854 \\
& \mathrm{~S}_{2}=\left(1,5 \mathrm{jt}^{-0,230}\right) *\left(15^{0,310}\right) \\
& *\left(20^{0,310}\right) *\left(3,32^{0,153}\right)=0,2624 \\
& \mathrm{~S}_{3}=\left(3,2 \mathrm{jt}^{-}\right. \\
& 0,230) *\left(18^{0,310}\right) *\left(25^{0,310}\right) *\left(6,3^{0,153}\right)=0,3335
\end{aligned}
$$

3. Menentukan Vektor $\mathrm{V}$ 


$$
\begin{aligned}
& \mathrm{V}_{1}=\frac{0,2854}{0,2854+0,2624+0,3335}=0,3471 \\
& \mathrm{~V}_{2}=\frac{0,2624}{0,2854+0,2624+0,3335}=0,3192 \\
& \mathrm{~V}_{3}=\frac{0,3335}{0,2854+0,2624+0,3335}=0,3335
\end{aligned}
$$

Dari hasil Vektor V yang di dapat maka rekomendasi alternatif yang di dapat dari hasil perangkingan adalah V1 yang memiliki nilai tertinggi yaitu 0,3471 . Adapun urutan dari nilai tertinggi ke nilai terendah adalah sebagai berikut :

Tabel 13. Nilai Akhir Setiap Printer

\begin{tabular}{|c|c|}
\hline Merk Printer & Nilai Akhir \\
\hline Epson L3110 & 0,3471 \\
\hline $\begin{array}{c}\text { Canon PIXMA } \\
\text { G3010 }\end{array}$ & 0,3335 \\
\hline HP DeskJet 2135 & 0,3192 \\
\hline
\end{tabular}

Berdasarkan Tabel 13 bahwa Epson L3110 mendapatkan nilai akhir tertinggi disusul Canon PIXMA G3010 dan HP DeskJet 2135. Sehingga dari hasil akhir tersebut didapatkan sebuah kesimpulan bahwa Epson L3110 dapat direkomendasikan sebagai pilihan utama bagi konsumen untuk membeli sebuah printer serta berdasarkan survei Epson L3110 menjadi pilihan bagi konsumen karena printer tersebut memiliki kecepatan tinta warna dan tinta hitam yang sangat baik jika dibandingkan dengan kedua merk printer lainnya.

\section{Simpulan}

Berdasarkan hasil penelitian yang telah di lakukan melakukan kuisioner kepada pegawai, disimpulkan bahwa tahapan yang menggunakan beberapa kriteria sebagai pertimbangan. Kriteria yang di pertimbangkan adalah Harga, Kecepatan Print Berwarna, Kecepatan Print Hitam Putih, dan Berat Print tersebut. Dari kriteria yang di dapat kemudian di pertimbangkan melakukan metode Weight produk sebagai yang menggunakan perkalian sebagai perhitungan untuk menghubungkan Atribut dan mendapatkan nilai yang tertinggi sebagai alternative terbaik. Hasil dari pengujian Metode Weight Produk pada tiap type jenis Printer yang di uji coba dapat di ketahui bahwa perangkingan yang di lakukan menggunakan Vektor $\mathrm{V}$ yang tertinggi yang akan menjadi alternatif terbaik pemilihan Printer yang bagus dan sesuai untuk pengguna dikantor nanti nya.

Dari hasil akhir yang diperoleh bahwa Epson L3110 dapat direkomendasikan sebagai pilihan utama bagi konsumen untuk membeli sebuah printer serta berdasarkan survei Epson L3110 menjadi pilihan bagi konsumen karena printer tersebut memiliki kecepatan tinta warna dan tinta hitam yang sangat baik jika dibandingkan dengan kedua merk printer lainnya.

\section{Daftar Pustaka}

[1] Amriana, A., Dodu, A.Y.E., Mas, P.R. 2020. Pendeteksian Kerusakan Printer menggunakan Metode Forward Chaining. ILKOM Jurnal Ilmiah. Vol II. No 1.

[2] Rusyamsi Lim. 2009. Cara Cepat Menjadi Teknisi Printer Canon Profesional. Jakarta: Elex Media Komputindo,

[3] Pardede, A.M.H., Ginting, B.S. 2013. Perancangan Sistem Pakar Deteksi Kerusakan Printer Canon Berbasis Web. Jurnal Kaputama. Vol VII. No. 1.

[4] Sitohang, H.T. Siboro, M.S. 2016. Journal of Informatics Pelita Nusantara. Vol I. No. 1.

[5] Kusumadewi, Sri. 2006. Fuzzy Multi-Attribute Decision Making (Fuzzy MADM). Yogyakarta : Graha Ilmu.

[6] Yoon, K.P., Hwng, C.L. 1989. Multiple Attribute Decision Making Methods: An Introduction. Thousand Oaks, US, SAGE Publications, Ltd. 